\title{
"Diesel-Gate" in risk reporting-An analysis of risk communication in annual reports using the example of a disruptive event
}

\author{
Deborah Nagel $^{1} \cdot$ Lisa Koep $^{2} \cdot$ Edeltraud Guenther $^{2} \cdot$ Thomas Günther $^{1}$ \\ Published online: 20 April 2020 \\ (c) The Author(s) 2020
}

\begin{abstract}
Using the example of VW's handling of "Diesel-Gate" in its corporate communications (suspected manipulation of vehicle emission test results discovered in 2015), we examine the effects of a disruptive event on corporate risk reporting. To this end, an evaluation in the form of a case study of external corporate communications in VW's annual reports covering the years 2012-2017 was carried out. Changes can be seen in VW's communication with shareholders following "Diesel-Gate", especially with regard to what topics were covered and the emotionality of the language. Among the strategies used for restoring the company's image, the company took pains to highlight corrective measures designed to avoid similar incidents in the future. The methodology presented in the paper can be applied to the analysis of similar events.
\end{abstract}

Keywords Risk Communication · Diesel Gate $\cdot$ Risk Management · CSR Reporting

\section{Introduction}

\subsection{Risk communication and "Diesel Gate"}

The issues raised by media surrounding the suspected manipulation of vehicle emission test results of diesel engines at Volkswagen (VW) represent a serious, disruptive event for VW. Of interest for corporate annual reporting is Diesel-

\footnotetext{
${ }^{1}$ In the discussions about alleged manipulations of diesel engines in exhaust emission tests, the term "Diesel-Gate" is often replaced by alternative terms such as "diesel issue", "diesel scandal", "vehicle emissions scandal", "emissions affair", as used by VW. See: https://de. wikipedia.org/wiki/Abgasskandal.
}

Permission The article was originally published in German as Nagel, D., Koep, L., Günther, T., Günther, E., 2018.

"Diesel-Gate" in der Risikoberichterstattung - Eine Analyse der Risikokommunikation in Geschäftsberichten am Beispiel eines disruptiven Ereignisses. Kapitalmarktorientierte Rechnungslegung. Heft 10, 421-430. (VHB D). With kind permission of Springer Nature and Handelsblatt Fachmedien $\mathrm{GmbH}$.

Edeltraud Guenther

ema-editor@mailbox.tu-dresden.de

1 Department of Business Management/Controlling, TU Dresden, Dresden, Germany

2 Department of Business and Sustainability Management, Technische Universität Dresden, 01069 Dresden, Germany
Gate's ${ }^{1}$ potential impact on tools of corporate communications, especially risk communication.

The following article presents a case study that takes a closer look at the effects of a single selected event on a company's risk communication tools. To this end, components of the company's annual report, specifically the risk and opportunity report and the chapter on diesel issues within the management report along with the Letter to the Shareholders will be examined.

As a mandatory component of the management report pursuant to Art. 315 (1) of the German Commercial Code (HGB), the risk and opportunity report represents a standard tool of risk reporting that German ${ }^{2}$ and international empirical studies ${ }^{3}$ with an additional focus on German risk reporting rely on.

At the same time, the empirical research is usually on a cross-sectional analysis of a two- or three-digit number of risk reports. More recently, automated text analyses have been used ${ }^{4}$ to try to increase the sample without having to abandon the methodology of content analysis. The analysis of the annual reports shows that VW included a separate chapter on the "diesel issue" in the annual reports from 2015 onwards. This part of the report was therefore also included in the analysis. It also emerged that "Diesel-Gate"

\footnotetext{
2 See Kajüter and Winkler (2003 pp. 217-228).

3 See Dobler et al. (2011 pp. 1-22).

4 See Hope et al. (2016 pp. 1005-1045).
} 
was extensively discussed in the Letters to the Shareholders, a notification that is not legally mandated.

Since empirical research shows risk reporting as a primarily narrative tool (rather than a monetary or quantitative tool) and essentially focused on the past and present (instead of the future), we have selected mixed qualitative and quantitative text analysis as the methodology underlying the present analysis. This way, the rhetorical methods and narratives used by a single, primarily affected company $(\mathrm{VW})$ in the body of text associated with a selected event ("Diesel-Gate") could also be examined. The surprising fact that verbal, qualitative reporting prevails among accountants and analysts in corporate opportunity and risk reports raises the question of what type of content is delivered by this method. Risk narratives, i.e. complex constructs of the effects and handling of risks, such as suspected vehicle emissions manipulations, represent a vantage point that is often neglected by researchers and practitioners in the accounting field. Typical risk narratives for crisis situations include, for instance, admissions of culpability and atonement, which will be specifically addressed below.

The use and analysis of narratives has gained additional importance in currently increasing non-financial reporting. Many reporters are faced with the question of whether CSR reporting, for instance, should be primarily assigned to accounting or corporate communications. Some companies reduced quantitative or monetary content in reports because corporate communications were designed to make the content of reports more user-friendly.

Finally, risk reporting also plays an important role in how processes are set up in the risk management system (e.g. according to DIN ISO 31000:2018). As a general rule, risks and opportunities in the company are first identified before they are evaluated and aggregated in quantitative or monetary terms. In addition to managing significant opportunities and risks, risk monitoring is used for reporting to internal and external recipients. As a result, risk reporting is an indispensable element of a risk management process at all companies. Accordingly, we have investigated for VW how the diesel issue has navigated VW's own risk management system from the perspective of a recipient of external communications.

\subsection{VW and "Diesel-Gate"}

During "Diesel Gate", suspected manipulations to circumvent legally prescribed limits for vehicle emissions were uncovered. The Notice of Violation of the US Environmental Protection Agency (EPA) published on 18th September 2015 provided information on illegal shut-off devices in the engine management of some VW diesel models. The EPA determined in independent tests that the carbon emissions of the VW turbocharged diesel engine with direct injection
(TDI) were significantly higher in real driving conditions than in the laboratory tests reported by VW. It was shown that, compared to VW's figures, forty times the amount of nitrogen oxides (NO. $\mathrm{x}$ ) was produced, which represents a significant violation of the legally prescribed limits for pollutant emissions in the USA. ${ }^{5}$

Initially, CEO Martin Winterkorn declared in his video message of 22th September 2015 that he supported a rapid and transparent investigation. At that time he was on record to have said:

The irregularities in our Group's diesel engines contradict everything that Volkswagen stands for. I also do not have the answers to all questions at this time. ${ }^{6}$

The following day, Winterkorn resigned as CEO. ${ }^{7}$ In his resignation statement he declared:

As Chairman of the Board of Management, I assume responsibility for the irregularities at Diesel Engines that have come to light and have therefore asked the Supervisory Board to discuss an agreement with me which will terminate my responsibility as Chairman of the Board of Management at Volkswagen Group. Although I am not aware of any misconduct on my part, I have decided to take this step in the interest of the company. ${ }^{8}$

In the following months, extensive internal and external investigations were carried out with the aim of investigating the issue at hand and providing answers to the question of culpability. In the investigations that followed, however, there were indications that, in addition to the managers involved in the device development, the CEO may also have been aware of the manipulation. ${ }^{9}$

Eleven million VW vehicles are affected worldwide. ${ }^{10}$ The group agreed to several settlements in the USA totaling more than 17 billion Euro along with compensation for vehicle owners. In Germany, the contractual and tort claims

\footnotetext{
5 See Volkswagen AG, Annual Report (2016, p. 49).

6 See Volkswagen AG, Annual Report (2015), download at: http:// hbfm.link/4024 (Downloaded on: 24th August 2018).

7 See (Unnamed author), Die VW-Abgas-Affäre: Eine Chronologie, NDR online (2015), updated: 7th August 2018, http://hbfm.link/4025 (Downloaded: 24th August 2018).

8 See Winterkorn, "Volkswagen war, ist und bleibt mein Leben", Manager Magazin online (2015) on 23rd September 2015. Download at: http://hbfm.link/4026 (Downloaded on: 24th August 2018).

${ }^{9}$ See unnamed author, Winterkorn wurde bereits 2014 per Notiz informiert, 3rd March 2016. Download at: http://hbfm.link/4027 (Downloaded on 24th August 2018).

${ }^{10}$ See Volkswagen AG, Annual Report (2017), available at: http:// hbfm.link/4029 (Downloaded on: 24th August 2018).
} 
of vehicle owners have not yet been fully resolved. ${ }^{11}$ In the 2015 financial year, VW generated a negative net income of -1.361 billion due to the financial burdens of the diesel crisis, ${ }^{12}$ the first negative result in over 20 years. This goes to show that the diesel scandal, in addition to substantial financial repercussions consisting of back taxes, penalties, sales slumps, provisions, recalls, retrofits, discounts for customers, had a significant impact on the image and reputation of the company itself, as well as on the entire automotive industry. ${ }^{13}$

Due to these circumstances, the VW Group offers a rich research context to investigate how the company's is handling and managing the risk resulting from the scandal through its crisis communications. The following analysis aims to answer the following three research questions using a case study ${ }^{14}$ methodology:

1. How does VW communicate risk in its annual reports?

2. How does VW reflect on and interpret the events in question?

3. How are narrative structures used to elicit emotions and thus control risk for the company?

\section{Methodology}

On the basis of a case study, we will examine the phenomenon of risk narratives in risk communication-in this case, a disruptive event-in more detail. Case studies are particularly suitable for scientific surveys to investigate current phenomena such as "Diesel-Gate", and to gain new insights.

In order to examine how the company communicatively manages the risk associated with the diesel issue, VW annual reports are subjected to both a qualitative and a quantitative analysis. The three annual reports from the period preceding the crisis (financial years 2012-2014) and the three reports following the announcement of the diesel issue (financial years 2015-2017) are used to shed a light on how the communicative dimension of reporting is changing. ${ }^{15}$ The German versions of the annual reports were downloaded from the Group website in February 2018. The body of texts examined consists of the Letter to Shareholders (at the beginning of the Annual Report, written by the respective Chairman of the Executive Board in the fiscal year un-

\footnotetext{
11 See Schäfer and Fuhrmann (2018), Zivilrechtliche und rechtsökonomische Überlegungen zum Dieselskandal der Volkswagen AG, 2018, dal der Volkswagen AG, 2018. Download at: http://hbfm.link/ 4028 (Downloaded on: 24th August 2018).

12 See Volkswagen AG, loc. cit. (Fn. 10).

13 See Fracarolli Nunes and Park (2016 pp. 288-302).

14 See Yin (2003, pp. 1-17).

15 See Volkswagen AG, Annual Reports of 2012-2014 and 2015-2017.
}

der review), the risk and opportunity reports in the Group Management Report, and the new chapters on the diesel issue introduced in the 2015-2017 reports. The material was then manually coded by two coders using qualitative methods of content analysis and quantitative methods and the data analysis software MAXQDA ${ }^{\mathrm{TM}}{ }^{16}$ The individual sentences represent the unit of investigation. ${ }^{17}$ Frequency of the coding of the individual categories, divided by the total number of sentences in the examined text, forms the basis of the quantitative evaluations. ${ }^{18}$ Moreover, the content analysis was also supported by LIWC software. In this process, the number of codes is divided by the text length. These values form the basis for the evaluations presented in the results section. In regular exchanges on the research observations, the researchers questioned their interpretations ${ }^{19}$ and thus participated in a process of so-called "communicative validity". ${ }^{20}$ The methodological procedural and analytical steps are shown in Fig. 1. While step 1 was carried out using inductive coding, subsections of steps 2-4 were processed using a deductive approach. In order to consider as many different aspects of VW's risk communication as possible, the analysis is based on four analytical steps. In the first step, a descriptive content analysis was carried out to identify relevant sections of text and topics covered. In a second step, a rhetorical analysis was carried out to examine the rhetorical situation, the rhetorical appeal and the linguistic quality of texts. In step three, the process steps of the risk management system of the DIN ISO 31000:2018 standard (risk identification, risk assessment, risk control) and risk monitoring underwent analysis. The fourth step was to analyse the reporting dimensions ${ }^{21}$ in terms of time line and the scope of the quantitative information.

\subsection{Descriptive content analysis}

In order to get a first impression of how "Diesel-Gate" topic was handled within the framework of VW annual reports, all documents to be examined were searched for relevant terms (e.g. Diesel, Abgas, NOx). That way, relevant sections of text could be identified. These were coded inductively and manually by two researchers using the program MAXQDA ${ }^{\mathrm{TM}}$. The purpose of this analysis step was to develop a deeper sense of the reports to be examined for further analysis. ${ }^{22}$

\footnotetext{
16 See Mayring (2010, pp. 601-613); Tausczik and Pennebaker (2010 pp. 24-54).

17 See Linsley and Shrives (2005 pp. 292-305).

18 See Höfer (2016, p. 85).

19 See Michalski (2004 pp. 977-999).

20 See Kvale (1995 pp. 19-40).

21 See Boesso and Kumar (2007 pp. 269-296).

22 See Krause et al. (2017 pp. 240-272).
} 


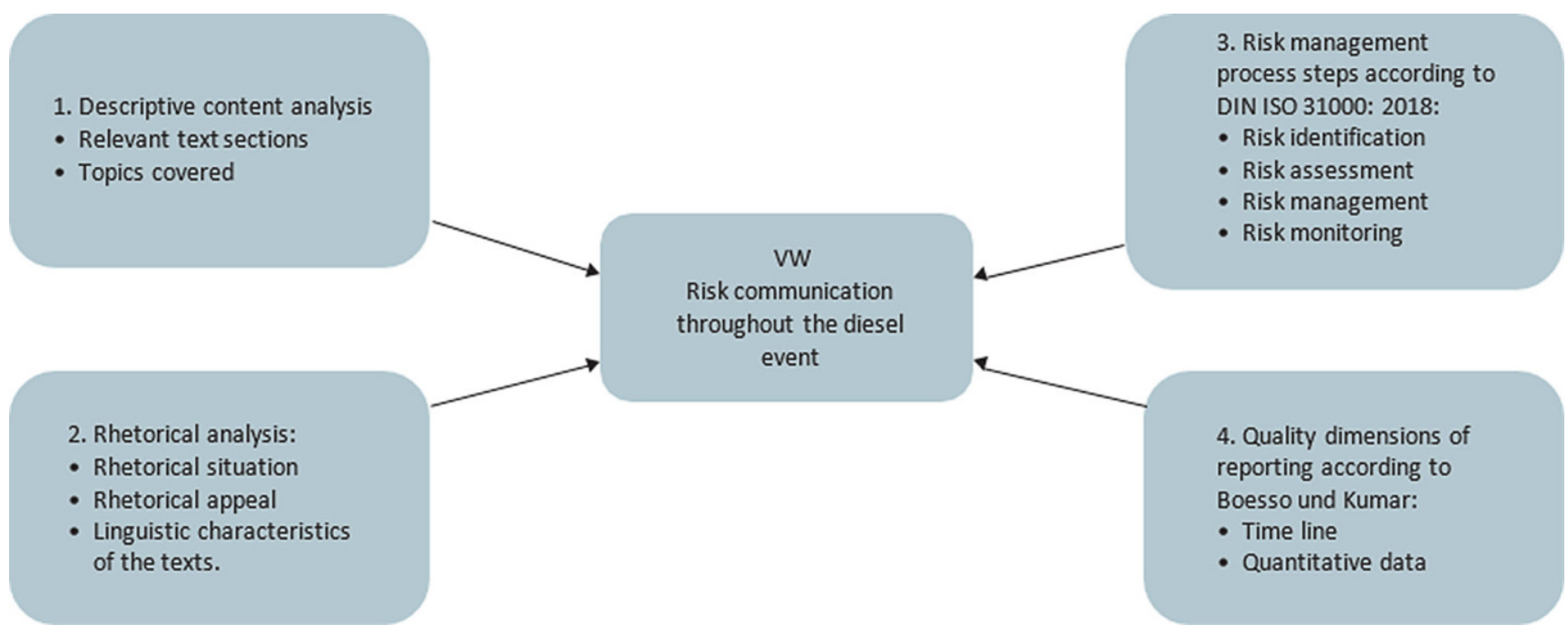

Fig. 1 Analytical steps

\subsection{Rhetorical analysis}

Classical rhetoric deals with the use of language and signs with the aim of convincing an audience. ${ }^{23}$ While the focus of rhetorical analyses has traditionally been on speeches, CEO statements and nar-ative annual reports are increasingly being analysed to examine rhetorical elements more closely. ${ }^{24}$ Rhetorical approaches focus on the persuasive aspect of corporate communication, scrutinising the "conscious selection of expressions, metaphors, symbols and language" 25 in order to convince the audience of the legitimacy and success of the organisation especially in times of crisis and change..$^{26}$ The theoretical approach of rhetorical analysis thus makes it possible to shed light on the shaping of perceptions as well as on argumentation and evidence schemes regarding the risks arising from the diesel issue, and to gain insights into the way a company tries to steer the social discourse on the diesel issue using persuasive rhetorical techniques.

In order to capture systematically the developing risk narratives of the VW Group, our methodological procedure is underpinned by a rhetorical analysis. "This choice is based on the thesis that" "the success or failure of claims to truthfulness [...] depends less on empirical verification than on their inherent logic and the narrative's rhetorical persuasiveness" 27 . Our focus is on the investigation of the rhetorical means the company uses to incorporate opinions processes into its annual reports to generate an active risk

${ }^{23}$ See Ihlen (2011, pp. 150-170).

24 See Laine (2009 S. 1029-1054); Merkl-Davies and Koller (2012 pp. 178-193).

25 See Laine (2009 pp. 1034).

26 See Merkl-Davies and Koller (2012 pp. 178-193).

${ }^{27}$ See Somers (2012, pp. 280). narrative. On this basis, an analysis of rhetorical elements is carried out with the aim of shedding light on the question of debt and the company's risk resulting from the diesel issue. Based on this evaluation, we determine the intended impact or function of the rhetorical means with regard to the communicative goal in response to the three research questions above.

A crisis such as the VW diesel issue poses dangers and risks for companies, as image, identity and reputation may incur damage in the short, medium and long term. Crisis communication may be used to purposefully reduce negative emotions experienced by stakeholders. Keeping negative emotions at bay thus reduces the risk of reputational loss that follows a crisis and the likelihood of negative word-of-mouth, while nudging sentiment toward purchase decisions. ${ }^{28}$ Since a crisis requires a special kind of urgency, well thought-out, stakeholder-oriented crisis communication is required to help a company reconstruct its desired image. Since crises can be caused by various factors, such as accidents that can be self-inflicted or caused externally, or by the intentional crossing of boundaries, ${ }^{29}$ communication strategies that incorporate such lessons are recommended. As a result, the use of specific strategies to restore reputation in the event of a crisis caused by a deliberate, self-inflicted infraction such as the VW diesel issue have been reommended. In particular, acceptance of culpability and asking forgiveness are often recommended strategies. ${ }^{30}$ Other strategies to restore a company's image are: denial,

\footnotetext{
28 See Coombs and Holladay (2007 pp. 300-312).

29 See Coombs (2004 pp. 265-289); Coombs (1995 pp. 447-476).

30 See Coombs (2004 pp. 447-476); Hearit (2006, pp. 204-218).
} 
evasion of responsibility, avoiding the appearance of assertiveness, and taking corrective action. ${ }^{31}$

In order to analyse the entire context, the rhetorical and communicative performance of the texts in the annual reports along with its linguistic elements have been evaluated. Drawing on rhetorical and linguistic elements, the approach of our analysis is based on Covino/Jolliffe, Covino/ Jolliffe $^{32}$. Our model is divided into three levels: rhetorical situation, rhetorical appeals, and linguistic characteristics of the texts. The three levels are explained below.

\subsubsection{Rhetorical situation}

The term "rhetorical situation" addresses the motive or need that prompts a person or speaker to write or speak. ${ }^{33}$ In addition, the rhetorical situation takes into account the interaction between audience and message, which is influenced by the motif as well as by ideas and attitudes projected by all protagonists. The rhetorical situation consists of the aspects "reason", "audience" and "framework". The context in which the text is written and read is examined. ${ }^{34}$ Fleshing out the context provides insights into the motives for communication. The audience consists of a group of people with whom the messenger wishes to communicate. The rhetorical framework consists of the options and limits the speaker has to consider. Hence, MAXQDA ${ }^{\mathrm{TM}}$ was used to carry out a qualitative analysis of the rhetorical situation, putting motivation, the audience and the context of the communication under the lens.

\subsubsection{Rhetorical appeal}

Classical rhetoric is characterised by three different but inseparable Aristotelian elements of logos (reason and consistency), ethos (authority and credibility of the speaker) and pathos (emotional appeal). ${ }^{35}$ With the first element, logos, an attempt is made to persuade by appealing to reason. Logic, reasoning, evidence and facts are used to support an argument. Pathos draws on the emotions and deeply rooted convictions of the listener and reader to encourage their investment in the topic. This strategy is designed to arouse emotions, such as joy and hatred, in the reader. In the context of business communication, the aim is usually to create a common bond of values, ${ }^{36}$, which can be achieved by using the corporate voice and invoking shared values through

\footnotetext{
31 See Benoit and Drew (1997, pp. 153-163).

32 See Covino and Jolliffe (1995, pp. 3-26).

33 See Bitzer (1968 pp. 1-14).

34 See Fn. 34.

35 See Aristoteles (2002), Rhetorik I,1,11 1355a7f.

36 See Hoffman and Ford (2010, pp. 185-208).
}

the increased use of "we". ${ }^{37}$ The third rhetorical element, ethos, underscores the speaker's credibility in order to gain the reader's trust. Taken together, these elements show the characteristics of a good argument and identify the dimensions of a persuasive appeal. ${ }^{38}$ Green $^{39}$ holds that, according to Aristotle, the three elements of rhetoric, logos, ethos and pathos can be used alternately to arouse the interests of others, to justify action as efficient or effective, and to appeal to socially accepted norms that help improve performance. Holt/Macpherson ${ }^{40}$ demonstrate that a mixture of logos, ethos and pathos is used to simultaneously take into account the interests of divergent interest groups and accommodate strategically diverse stakeholders.

\subsubsection{Linguistic characteristics of texts}

For linguistic analysis, the German version of the computer-aided quantitative text analysis software, Linguistic Inquiry and Word Count (LIWC), has been used. The software stems from the field of psychology and analyses texts by matching each word with a dictionary. Divided into 74 word fields by independent evaluators, the dictionary consists of more than 2300 words $^{41}$ such as those conveying emotion, temporal dimension, negations, direction and monetary elements ${ }^{42}$. ${ }^{43}$ The software was used, for example, to analyse media articles in the wake of the earthquake and tsunami in Japan. Table 1 shows the word fields evaluated in our analysis. The words assigned to the respective categories can be gleaned from Wolf's ${ }^{44}$ list.

\subsection{Risk management process steps according to DIN ISO 31000: 2018}

The risk management process is detailed in the DIN ISO standard 31000:2018. According to the DIN ISO standard, the process consists of three stages: risk identification, risk assessment (risk analysis and evaluation) and risk control. Risk identification aims to identify sources of risk on the basis of historical data, theoretical analyses and expert opinions. As such, it helps to determine relevance. Risk analysis considers the level of risk and likelihood of its occurrence; extent of the effect and likelihood of occurrence are assigned to relevance. Risk evaluation classifies the acceptability or tolerability of risks against their ability to create

\footnotetext{
37 See Femers-Koch and Molthagen-Schnöring (2017 pp. 325).

38 See Holt and Macpherson (2010 pp. 20-42).

39 See Green (2004 pp. 653-669).

40 See Fn. 39.

41 See Wolf et al. (2008 pp. 85-98).

42 See Tausczik and Pennebaker (2010 pp. 24-54).

43 See Sevincer et al. (2014 pp. 1010-1017).

${ }^{44}$ See Fn. 42.
} 
Table 1 LIWC word fields

\begin{tabular}{ll}
\hline Word field & Evaluation category \\
\hline Positive emotions & Mood \\
Negative emotions & (Rhetorical Analysis-DICTION) \\
1 st Person singular & $\begin{array}{l}\text { Personal information } \\
\text { (st Person Plural }\end{array}$ \\
3rd Person & \\
Reference to others & \\
Temporary character & Assertiveness of statements (Rhetorical Analysis-DICTION) \\
Certainty & \\
Acceptance & Question of culpability \\
To reach & (Rhetorical Analysis-DICTION) \\
Words longer than six characters & Syntax \\
Comma & (Rhetorical analysis-syntax) \\
Length of sentence & \\
Past & Time line \\
Presence & \\
Future & \\
Numbers & \\
\hline
\end{tabular}

${ }^{a}$ See Fn. 21

value. Finally, risk management is dedicated to the selection and implementation of procedures and measures aimed at changing risks. In addition, risks should be monitored on an ongoing basis. Risk management is understood as an ongoing process in which planning, implementation, monitoring and improvement take place continuously. The steps involved in the process were identified during the manual content analysis of the report parts examined.

\subsection{Quality dimensions of reporting according to Boesso/Kumar}

Boesso/Kumar ${ }^{45}$ analyses the quality of narrative reporting; they distinguish between quantitative and qualitative, monetary and non-monetary as well as past and futureoriented statements. Quantitative, monetary and forwardlooking statements are considered to be of higher quality because the information is more meaningful to users of the report. ${ }^{46}$ The scope of quantitative statements, as well as the time reference, can be analysed using the LIWC software. The monetary dimension was encoded manually by the authors.

\section{Results}

By and large, the risk and opportunity reports, as well as the report section on diesel issues, reveal a rather neutral and impersonal style of reporting. For instance, there are

\footnotetext{
45 See Fn. 21.

46 Linsley and Shrives (2005 pp. 292-305).
}

communications of facts or logical chains of argumentation, some of which are supported by figures of monetary values. The report section on the diesel issue focuses on the sequence of events, the extent of the damage and the question of culpability. The risk and opportunity report presents the specific risks, sometimes supplemented by assessments and control measures:

In December 2017, a lawsuit for damages on the assigned claims of approximately 6000 customers against Volkswagen AG was lodged in Switzerland in the amount of approximately 30 million Swiss francs. ${ }^{47}$.

By contrast, the Letter to Shareholders is addressed directly to shareholders, using elaborate rhetorical tools to appeal to emotions and credibility. The Letter to the Shareholders focuses in particular on company values, the past financial year and future outlook:

So if you asked me today: "Is Volkswagen a good company?" my answer would be: "Yes, Volkswagen is a highly successful global corporation." Yes, we are investing all our energy in the future of mobility and, by extension, in our own future. And yes, we at Volkswagen recognise how vital a solid foundation of values and a healthy corporate culture are for our existence and survival. ${ }^{48}$.

\footnotetext{
47 See Volkswagen AG, loc. cit. (Fn. 10), p. 180.

48 See Volkswagen AG, loc. cit. (Fn. 10), p. 9.
} 
The following paragraphs provide an initial compilation of the results of the descriptive content analysis. Next is a presentation of the results of the rhetorical analysis and an evaluation of the changes in the report contents over time based on the process steps of the risk management system. Finally, the results of reporting metrics are presented. ${ }^{49}$

\subsection{Observations on the content of the descriptive content analysis}

The content analysis of the reports shows that, especially in the Letters to Shareholders, there are clear topical differences in reporting before and after the diesel issue. Prior to that, the focus was on the changes in the market, the company's successive repositioning and adaptation to changed conditions, its solid environmental performance, growth and success and about the gratitude it owned to shareholders:

Our company continues to offer excellent prospects because we stand for innovative strength, competitiveness and financial substance..$^{50}$.

The topical focus shifted following the emergence of the diesel issue. The company sees the crisis as an opportunity, points to an internal learning process and asking shareholders not to lose faith:

"And that's because the measures we're taking now will succeed in making Volkswagen a better company." A group that boldly takes the future into its own hands and grows sustainably with an eye on longterm goals for its customers, employees and partners, for our society and last but not least for you, our shareholders. ${ }^{51}$.

Although the messaging is commendable in terms of effective crisis communication ${ }^{52}$, the company at no time admits to any blame.

\subsection{Rhetorical analysis}

\subsubsection{Rhetorical situation}

The rhetorical situation is composed of the aspects "general conditions", "audience" and "motivation". The external requirement for companies to disclose opportunities and risks within the framework of the group management report of the annual report for German companies is based on Art.

\footnotetext{
49 See Fn. 21.

50 VW Volkswagen AG, Annual Report Group (2014, p. 14).

51 Volkswagen AG, loc. cit. (Fn 6), p. 9.

52 See Hearit, loc. cit. (Fn. 31), pp. 447-476.
}

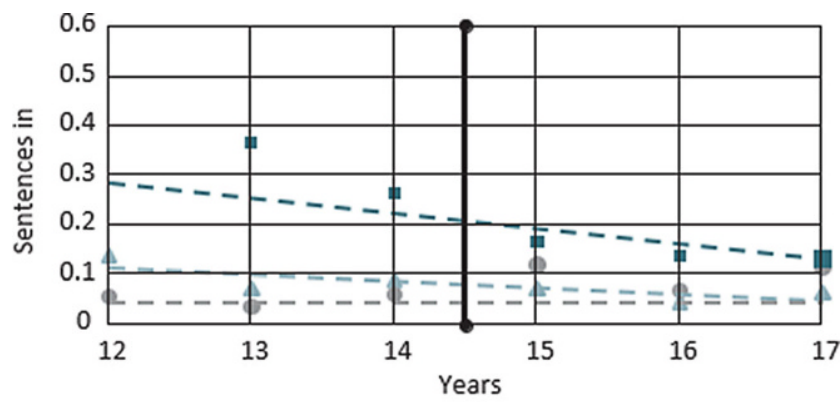

$\triangle$ Pathos Ethos $\square$ Logos $\leadsto$ Diesel event

Fig. 2 Appeal-Letter to the Shareholders

315 (1) HGB. Risk information in annual reports is primarily targeted at investors, ${ }^{53}$ but also at stakeholders who need the information to assess the company's risks. ${ }^{54}$ The goals that companies pursue with the publication of risk information are manifold. Since the requirement to publish risk information is mandated by law while the specifics are left to businesses, ${ }^{55}$ different approaches, motives and different economic theories may result in different ways of publishing risk information. For example, comprehensive risk information can help to improve the company's reputation by signaling transparency from the perspective of "legitimacy theory" ${ }^{56}$ From the perspective of the "Proprietary Cost Theory", there is a conflict of objectives between the publication of comprehensive information to reduce the information asymmetry of investors, and the indirect cost of third parties using this information to the detriment of the company (e.g. by competitors or lenders). ${ }^{57}$ The question of which motives prevail in the specific Case, and what advantages and disadvantages for the VW AG, remains open. This is where the following analyses come in-detailing current risk reporting practices, and the changes to risk reporting practices before and after the diesel issue.

\subsubsection{Rhetorical appeal}

Regarding the type of argument (appeal), the manual analysis shows that both the risk and opportunity report and the report section on diesel issues essentially employ logical arguments (logos), revealing only rare instances of ethos or pathos. In the Letters to Shareholders, all three types of appeals are utilised. This procedure follows the method of

\footnotetext{
53 See Hope et al. (2016 pp. 1005-1045).

54 See Fn. 17.

55 See Dobler (2008 pp. 184-206).

56 See Ntim et al. (2013 pp. 363-383).

57 See Abraham and Shrives (2014 pp. 91-107).
} 

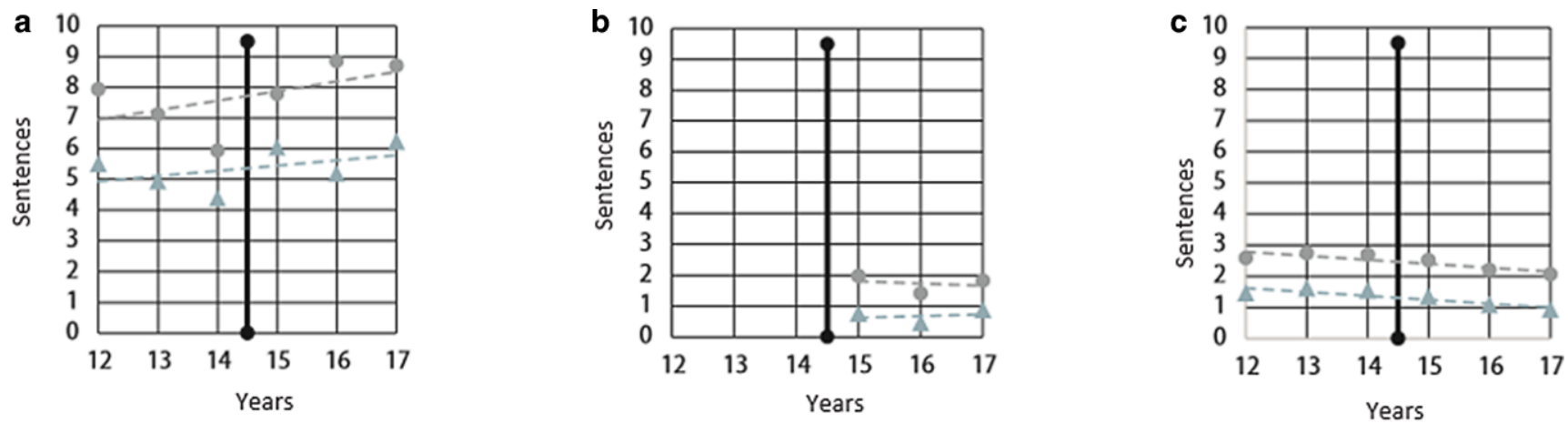

Reference to same person $\bigcirc$ Reference to others

Fig. 3 Personal language. a Letter to the Shareholders; b Diesel issue; c Risk and opportunity report
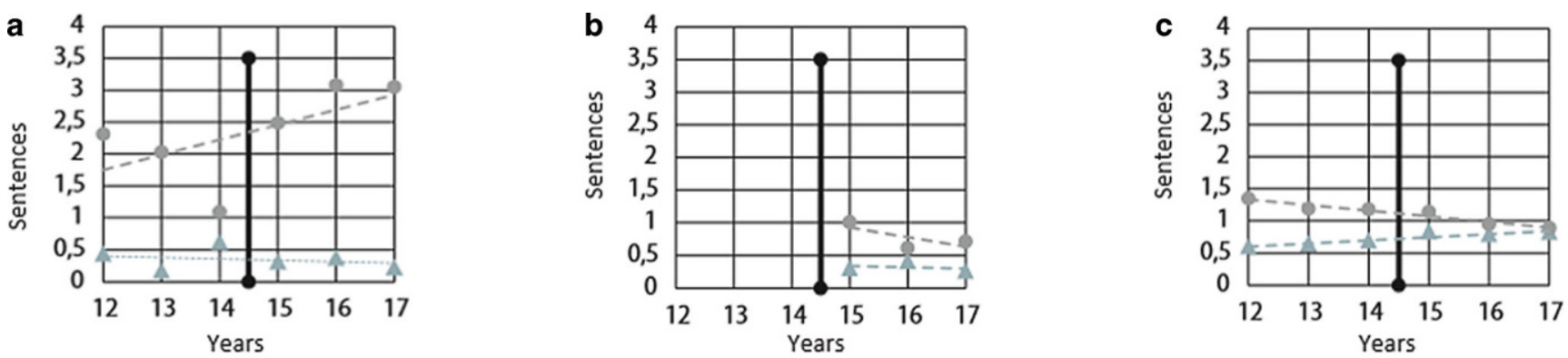

\section{Preliminary statements Statements expressing certainty}

Fig. 4 Statement's degree of assertiveness. a Letter to the Shareholders; b Diesel issue; $\mathbf{c}$ Risk and opportunity report

argumentation espoused by Green ${ }^{58}$ and Holt/Macpherson ${ }^{59}$, by using the different argumentation options alternately. Fig. 2 shows change in the form of argumentation in the Letters to Shareholders over the period under review. After the diesel issue came to the surface, there has been a reduction of logical argumentation (logos). By contrast, credibility arguments (ethos) now occur more frequently. This indicates a possible perceived need to emphasise the company's credibility to the shareholders, rather than focus on possibly-less-than-favorable facts:

We are doing everything we can to overcome this crisis: effective technical solutions for our customers and trustful cooperation with all responsible authorities amidst full transparency will help us get to the bottom of what happened. ${ }^{60}$

It also becomes clear that the frequency of emotional arguments (pathos) fluctuates within a narrow range.

\footnotetext{
58 See Fn. 40.

59 See Fn. 39 pp. 20-42.

60 Volkswagen AG, loc. cit. (Fn. 6), p. 7.
}

\subsubsection{Linguistic characteristics of texts}

With regard to the linguistic characteristics, the reference to persons, the certainty of statements, the communication of culpability, as well as the mood of the report sections were examined. Fig. 3 shows that particularly important in the Letters to Shareholders-but hardly ever in the report sections opportunity report and diesel issues-personal language is used in reference to the company, and shareholders are addressed directly. A review of the Letters to the Shareholders reveals more personal lines of arguments after the emergence of the diesel issue. After the diesel issue, a more frequently chosen direct approach vis-a-vis shareholders points to attempts at more personal communication for the purpose of adding more credibility to information. ${ }^{61}$

With respect to the assertiveness of statements made, Fig. 4 shows that, from a linguistic point of view, significantly more statements expressing certainty are made than statements expressing a degree of uncertainty. In the risk and opportunity report, the curves converge following the diesel issue. This could indicate a higher degree of uncertainty regarding risks and opportunities. It is also striking that the number of statements expressing certainty in the

${ }^{61}$ See Asay et al. (2018 pp. 68-69). 

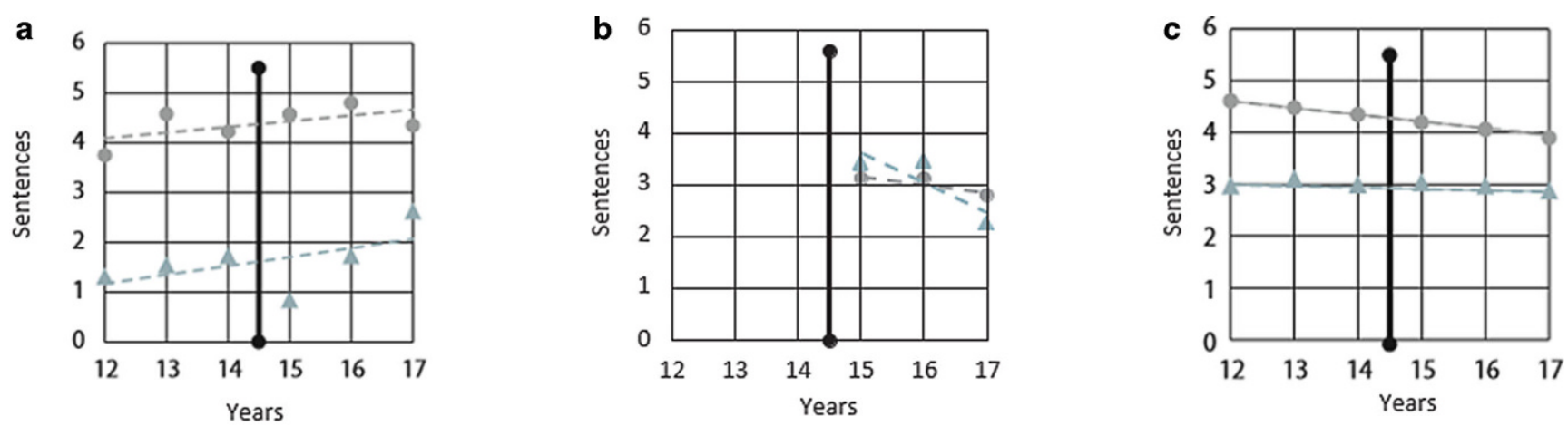

Acknowledgement Successes

Fig. 5 Question of culpability. a Letter to the Shareholders; b Diesel issue; c Risk and opportunity report
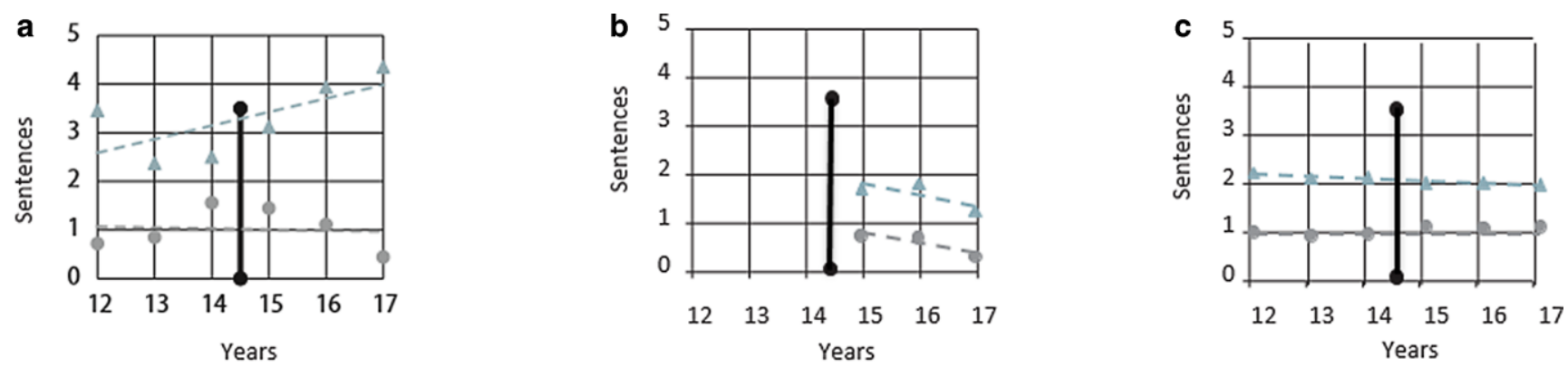

\section{Positive Emotions Negative Emotions}

Fig. 6 Mood. a Letter to the Shareholders; b Diesel issue; c Risk and opportunity report

Letters to Shareholders in the reporting years following the diesel issue is very high compared with those from reporting years before the crisis. This, too, in the sense espoused by Coombs/Holladay, ${ }^{62}$ could indicate a communication strategy on the part of VW AG that aims to provide shareholders with a sense of security.

Fig. 5 summarises the results on the question of culpability. It becomes apparent that significantly more communication has taken place about what the company has achieved or will achieve, while the topic of acceptance of culpability receives much less attention. This conspicuous absence is particularly evident in the Letters to Shareholders, whereby the frequency of cited insights increases significantly after the diesel issue. The risk and opportunity reports show a relatively constant level of both frequencies. No change is discernible between the reports before and after the diesel issue emerged. It is also clear that this correlation does not apply in the report section on diesel. In 2015 and 2016, these parts of the report put more emphasis on insights gained than on successes. The diesel section of the report clearly differs from the other two sections of the report that have been examined, communicating issues more directly

62 See Fn. 28. and emphasising the need for corrective action as a strategy to restore the ${ }^{63}$ company's image.

The analysis of the mood (see Fig. 6) shows that communication of positive emotions occurs more frequently within the Letters to Shareholders, and less in the other two parts of the report. This result matches the already identified strong logical reasoning in these two parts of the report. The levels of emotion expressed in the risk and opportunity reports, and in the sections of the report on diesel technology, are constant. It is also apparent that communication of positive emotions in the Letters to Shareholders increases after the diesel issue while communication of negative emotions in these three reports steadily decreases. This may indicate that VW AG was attempting to get shareholders to buy into a positive outlook even as the crisis unfolded, by communicating more positive and fewer negative emotions. ${ }^{64}$

The evaluation of the syntax shows that the Letters to Shareholders tended to use fewer long words which indicates the use of simpler language. There is a slight increase in the number of commas in the Letters to Shareholders after the diesel issue. The length of the sentences shows few

\footnotetext{
63 See Fn. 32.

64 See Fn. 28.
} 



\section{Risk identification \\ Risk assessment \\ Risk management $>$ Risk monitoring}

Fig. 7 Risk management system. a Diesel issue; b Risk and opportunity report

deviations from the norm. The syntax of the examined report parts in the comparison before and after the occurrence of the diesel topic reveals no significant findings.

Visually vivid language and figures of speech are mostly found in the Letters to Shareholders. A significant difference in the frequency of use of figurative language before and after the diesel issue has not been observed.

\subsection{Steps of the risk management process according to DIN ISO 31000:2018}

The steps involved in the risk management system processes relating to the diesel issue are primarily addressed in the section on diesel issues and in the risk and opportunity report (Fig. 7). The risk and opportunity report shows that in the first report after the diesel issue all four steps were addressed with low frequency. This gives rise to the assumption that the risk management process had not yet fully unfolded due to the unexpected emergence of the diesel issue. For 2016, a significant increase in the process steps of risk identification and risk assessment is visible. However, few clues to risk management and risk monitoring steps could be found. The 2017 Risk and Opportunity Report contains few clues to risk identification and assessment. However, there's a rapid increase in the number of mentions in the area of risk management. None of the three years since the diesel issue showed a larger number of clues to risk monitoring. It is not unreasonable to expect that this aspect will gain more prominence in reports going forward, as the risk management process is currently not yet sufficiently advanced to implement measures for monitoring risks in the future. However, it is apparent that the risk management process has so far been reflected in the risk and opportunity reports. The correlations are less clear in the report section on diesel issues. A significant amount of space is devoted to relatively large numbers of risk control measures or the handling of risks. It is striking that a risk assessment was carried out in 2016, of all years. Risk identification is addressed frequently in 2015 and 2016 but less so in 2017. In addition, a comparatively large number of risk monitoring measures designed to prevent events such as the diesel crisis from reoccurring are mentioned. This result matches the previous observation of diverging communication behaviour in the report section on diesel issues, e.g. with regard to the assertiveness of statements.

\subsection{Quality dimensions of reporting according to Boesso/Kumar}

Evaluations of the Boesso/Kumar analysis grid Boesso/ Kumar $^{65}$ (Fig. 8 and 9) make it clear that the report section on diesel issues is strongly focused on the past. This confirms the observation that especially in this area, the sequence of events following the occurrence of the diesel issue is presented in detail. On the other hand, letters to shareholders tend to focus on current events-especially during the three years following the diesel issue. Statements on the future of the company, or on future measures, are rarely identified across all parts of the report. This finding confirms the results of previous research on risk reporting. ${ }^{66}$ The results are surprising with regard to how risk management is used in the company to identify future risks.

In addition, it has been shown that the amount of quantitative data communicated in the Letters to Shareholders decreases after the diesel issue. The frequency of quantitative disclosures in the risk and opportunity report and in the report section on diesel issues increases after the diesel issue. This result is consistent with the results of the risk management system in the sense of expanding risk assessment and quantification. The amount of monetary information supplied as a subset of quantitative information also shows a very low frequency. That result, too, is consistent with the results of previous research. ${ }^{67}$

\footnotetext{
65 See Fn. 21.

66 See Fn. 3.

67 See Fn. 3.
} 


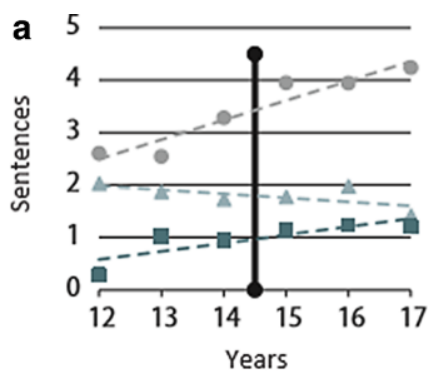

Past

Presence
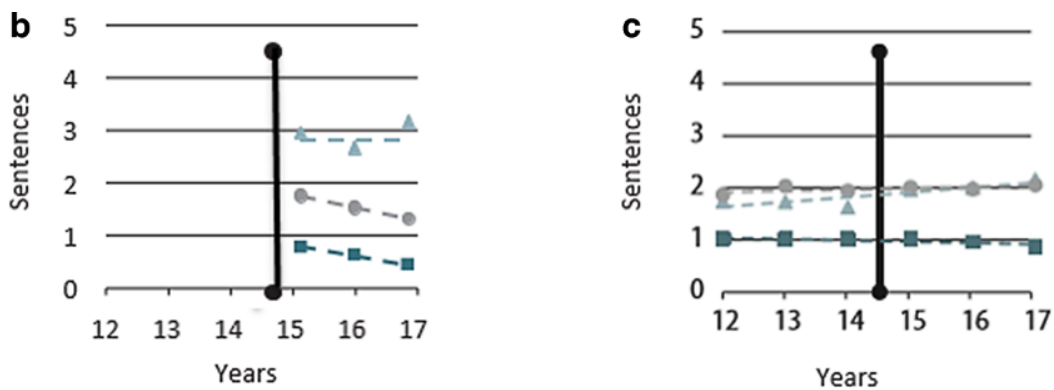

Fig. 8 Time line. a Letter to the Shareholders; b Diesel issue; c Risk and opportunity report
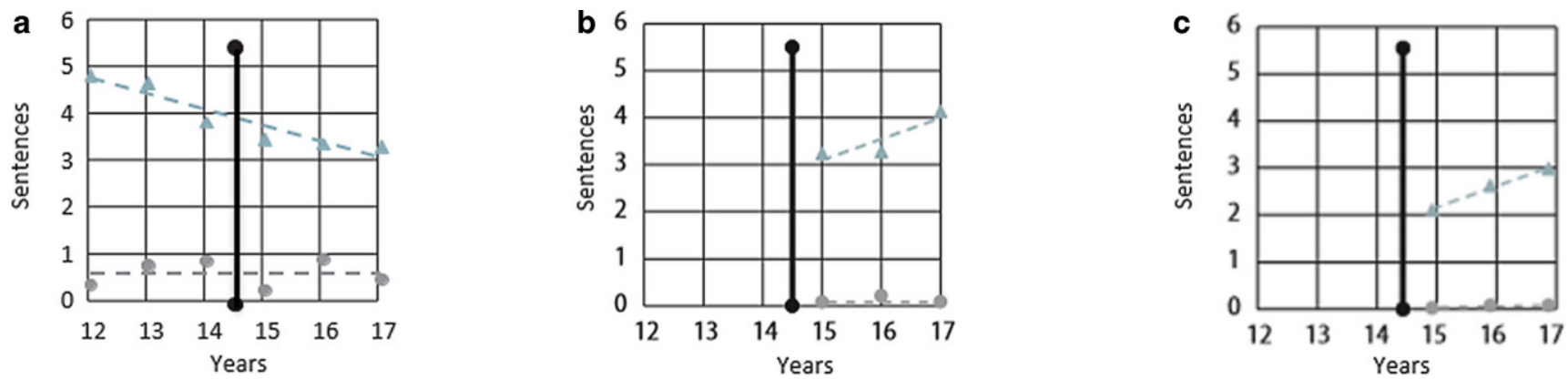

Quantitatively Monetary

Fig.9 Quantitative Data. a Letter to the Shareholders; b Diesel issue; c Risk and opportunity report

\section{Summary and discussion}

In summation, it has been observed that topics discussed have shifted since the diesel issue was addressed in the Letter to Shareholders-from previous successes, to learning processes that the company has been advised to embrace. After the diesel issue, communications displayed an uptick in personal language, and arguments have been made highlighting the company's credibility, rather than plain facts. In addition, shareholders are presented with imagery eliciting positive emotions, as many statements express a high degree of certainty. The report section on diesel differs from the other report sections; in this part of the report, VW AG may be attempting to provide the most comprehensive and neutral information possible for readers with a strong interest, without tying it to the usual reporting structure. The implementation of the risk management system is particularly evident in the risk and opportunity reports.

As a result, the following key results emerge with regard to the research questions that have been posed:

1. How does VW communicate risk in its annual reports?

- VW has added a separate section on the diesel issue to its annual report.
- However, straightforward and fact-based information is primarily communicated in the Risk and Opportunities Report and in the separate section on the diesel/ emissions topic.

2. How does VW reflect on and interpret the events in question?

- There has been comprehensive detailing and reflection of the events in the annual reports since 2015 .

- The question of culpability is not discussed in detail, but legal implications have been laid out.

3. How are narrative structures used to elicit emotions and thus manage company risk?

- The emotional appeal to the reports' readers (especially shareholders) is addressed in the Letters to the Shareholders, where an increasingly positive, emotional language is used.

- In addition, following "Diesel-Gate", statements expressing certainty can be found in the Letters to Shareholders with increased frequency.

- Amongst the strategies for restoring the company's image, corrective measures are recommended in order to avoid similar scenarios in the future.

- VW employs the narrative of the learning organisation to signal to readers that similar incidents will not occur in the future. 
This study focused on external corporate communication in the form of VW business reports. Since the reception of the information by readers of the report users was not investigated, no evaluation can be made as to whether this type of risk communication is successful in mitigating the negative perception of a crisis. As the company's key economic figures show a positive trend since $2016,{ }^{68}$, it can be assumed that the company's overall strategy for dealing with the crisis has been successful.

In the present study, a single case analysis was carried out, limited to VW. However, since the emissions affair also affects other automotive companies, the methodological approach presented here could be extended to other cases in order to identify similarities and differences and thus generate more robust findings regarding the construction of risk narratives in business reports. Furthermore, it may be possible to apply the methodology to other industries and scenarios.

\section{Funding Open Access funding provided by Projekt DEAL.}

Conflict of interest D. Nagel, L. Koep, E. Günther and T. Günther declare that they have no competing interests. The public sponsor had no role in the design of the study, in the collection, analyses, or interpretation of data, in the writing of the manuscript, and in the decision to publish the results.

Open Access This article is licensed under a Creative Commons Attribution 4.0 International License, which permits use, sharing, adaptation, distribution and reproduction in any medium or format, as long as you give appropriate credit to the original author(s) and the source, provide a link to the Creative Commons licence, and indicate if changes were made. The images or other third party material in this article are included in the article's Creative Commons licence, unless indicated otherwise in a credit line to the material. If material is not included in the article's Creative Commons licence and your intended use is not permitted by statutory regulation or exceeds the permitted use, you will need to obtain permission directly from the copyright holder. To view a copy of this licence, visit http://creativecommons.org/licenses/by/4. $0 /$.

\section{References}

\section{Cited literature}

Abraham S, Shrives PJ (2014) Improving the relevance of risk factor disclosure in corporate annual reports. $\mathrm{Br}$ Account Rev 46(1):91-107

Aristoteles (2002) Rhetorik. Akademie-Verlag, Berlin

Asay HS, Libby R, Rennekamp KM (2018) Do features that associate managers with a message magnify investors' reactions to narrative disclosures? Account Organ Soc 68:1-14

Benoit WL, Drew S (1997) Appropriateness and effectiveness of image repair strategies. Commun Reports 10(2):153-163

Bitzer LF (1968) The rhetorical situation. Philos Rhetor 1:1-14

Boesso K, Kumar K (2007) Drivers of corporate voluntary disclosure: a framework and empirical evidence from Italy and the United States. Account Auditing Account J 20(2):269-296
Coombs WT (1995) Choosing the right words: the development of guidelines for the selection of the "appropriate" crisis-response strategies. Manag Commun Q 8(4):447-476

Coombs WT (2004) Impact of past crises on current crisis communication: insights from situational crisis communication theory. J Bus Commun 41(3):265-289

Coombs WT, Holladay SJ (2007) The negative communication dynamic: exploring the impact of stakeholder affect on behavioral intention. J Commun Manag 11(4):300-312

Covino WA, Jolliffe DA (1995) Rhetoric: concepts, definitions, boundaries. Allyn and Bacon, Boston

Dobler M (2008) Incentives for risk reporting-A discretionary disclosure and cheap talk approach. Int J Account 43(2):184-206

Dobler M, Lajili K, Zéghal D (2011) Attributes of corporate risk disclosure: an international investigation in the manufacturing sector. J Int Account Res 10(2):1-22 (https://doi.org/d9kx7f)

Femers-Koch S, Molthagen-Schnöring S (2017) Textspiele in der Wirtschaftskommunikation: Texte und Sprache zwischen Normierung und Abweichung. VS, Wiesbaden

Green SE (2004) A rhetorical theory of diffusion. AMR 29(4):653-669

Hearit K (2006) Crisis management by apology: corporate response to allegations of wrongdoing. Lawrence Erlbaum, Mahwah

Höfer J (2016) Determinanten der Zukunftsorientierung in der Berichterstattung deutscher Aktiengesellschaften: Eine panelökonometrische Untersuchung der HDAX-Unternehmen von 2003 bis 2012. Hampp, Mering.

Hoffman MF, Ford DJ (2010) Organizational rhetoric: situations and strategies. Sage, Thousand Oaks

Holt R, Macpherson A (2010) Sensemaking, rhetoric and the socially competent entrepreneur. Int Small Bus J 28(1):20-42

Hope OK, Hu D, Lu H (2016) The benefits of specific risk-factor disclosures. Rev Account Stud 21(4):1005-1045

Ihlen $\varnothing(2011)$ Corporate Social Responsibility und die rhetorische Situation. In: Raupp J, Jarolimek S, Schultz F (eds) Handbuch CSR. VS, Wiesbaden, pp 150-170

Kajüter P, Winkler C (2003) Die Risikoberichterstattung der DAX100Unternehmen im Zeitvergleich : Ergebnisse einer empirischen Untersuchung. KoR Int Cap Mark Oriented Accounting FRS 3(5):217-228

Krause J, Sellhorn T, Ahmed K (2017) Extreme uncertainty and forward-looking disclosure properties. Abascus 53(2):240-272

Kvale S (1995) The social construction of validity. Qual Inq 1(1):19-40

Laine M (2009) Ensuring legitimacy through rhetorical changes?: A longitudinal interpretation of the environmental disclosures of a leading Finnish chemical company. Account Auditing Account J 22(7):1029-1054

Linsley PM, Shrives PJ (2005) Examining risk reporting in UK public companies. J Risk Finance 6(4):292-305. https://doi.org/10.1108/ 15265940510613633

Manager Magazin online (2015) Volkswagen war, ist und bleibt mein Leben. http://hbfm.link/4026. Accessed 24 Aug 2018

Mayring P (2010) Qualitative content analysis. In: Mey G, Mruck K (eds) Handbook qualitative research in psychology. VS, Wiesbaden, pp 601-613

Merkl-Davies D, Koller V (2012) 'Metaphoring' people out of this world: a critical discourse analysis of a chairman's statement of a UK defense firm. Account Forum 36(3):178-193

Michalski S (2004) Types of customer relationship ending processes. J Mark Manag 20(9-10):977-999

NDR online (2015) Die VW-Abgas-Affäre: Eine Chronologie. http:// hbfm.link/4025. Accessed 24 Aug 2018

Ntim C, Lindop S, Thomas DA (2013) Corporate governance and risk reporting in South Africa: a study of corporate risk disclosures in the pre- and post-2007/2008 global financial crisis periods. Int Rev Financial Analysis 30(C):363-383

Nunes MF, Park CL (2016) Caught red-handed: the cost of the Volkswagen Dieselgate. J Glob Responsib 7(2):288-302

68 Volkswagen AG, loc. cit. (Fn. 10). 
Schäfer HB, Fuhrmann BW (2018) Civil Liability Problems of the Volkswagen Diesel Scandal. SSRN. http://hbfm.link/4028. Accessed 24 Aug 2018

Sevincer AT, Wagner G, Kalvelage J, Oettingen G (2014) Positive thinking about the future in newspaper reports and presidential addresses predicts economic downturn. Psychol Sci 25(4):1010-1017

Somers MR (2012) Fear and terror of the public. The narrative discourse of the Anglo-American citizenship theory. In: Arnold M, Dressel G, Viehöver W (eds) Erzählungen im Öffentlichen. VS, Wiesbaden, pp 273-309

Tausczik YR, Pennebaker JW (2010) the psychological meaning of words: LIWC and computerized text analysis methods. J Lang Soc Psychol 29(1):24-54

Volkswagen AG (2015) Annual Report 2015. http://hbfm.link/4024. Accessed 24 Aug 2018

Volkswagen AG (2017) Annual Report 2017. http://hbfm.link/4029. Accessed 24 Aug 2018
Volkswagen AG (2014) Annual Report Group 2014

Volkswagen AG (2016) Annual Report 2016

Wolf M, Horn A, Mehl MR, Haug S, Pennebaker JW, Kordy H (2008) Computer-aided quantitative text analysis: equivalence and robustness of the German version of the Linguistic Inquiry and Word Count. Diagnostica 54(2):85-98

Yin RK (2003) Case Study Research: Design and Methods, 6th edn.

\section{Further reading}

Manager Magazin online (2016) Winterkorn wurde bereits 2014 per Notiz informiert. http://hbfm.link/4027. Accessed 24 Aug 2018

Waymer D, Heath RL (2007) Emergent agents: The forgotten publics in crisis communication and issues management research. J Appl Commun Res 35(1):88-108 